\title{
XXI. On magnetic tractive force
}

\section{E. Taylor Jones D.Sc.}

To cite this article: E. Taylor Jones D.Sc. (1896) XXI. On magnetic tractive force, Philosophical Magazine Series 5, 41:250, 153-167, DOI: $10.1080 / 14786449608620835$

To link to this article: http://dx.doi.org/10.1080/14786449608620835

$$
\text { 曲 Published online: } 08 \text { May } 2009 .
$$

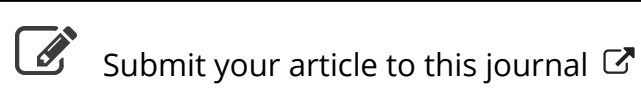

\footnotetext{
Џll Article views: 2
}

Q View related articles $\asymp$

4 Citing articles: 2 View citing articles 
I.ONDON, EDINBURGH, AND DUBLIN

\title{
PHILOSOPHICAI، MAGAZINE
}

\author{
AND \\ JOURNAL OF SCIENCE.
}

[FIFTH SERIES.]

$M A R C H 1896$.

XXI. On Magnetic Tractive Force ". By E. TAYLoR Jones, D.Se., Assistant Lecturer in Physics in the University College of North Wales, formerly Science Scholar of Royal Conmission for Exhibition of $1851 \dagger$.

TN a former paper $\ddagger$ an account was given of experiments 1 in which the value of the magnetic tractive force of a divided ellipsoid was found to agree within 1 per cent. with Maxwell's expression $B^{2} / 8 \pi$ for the electromagnetic stress in the narrow air-space between the two halves, for inductions between 6000 and 20,000 C.G.S.

In the present paper further experiments will be described, the chief object of which was to test whether the same agreement existed at much higher inductions. Since the magnetizing force $\mathrm{H}$ in the iron was very small in comparison with the induction $B$ in the former experiments, these cannot be considered as deciding between Maxwell's expression $\mathrm{B}^{2} / 8 \pi$ and, for instance, the expression $2 \pi \mathrm{I}^{2}$, which has also been given as the value of the tractive force $\$$.

In order to complete the test it was necessary to continue the experiments to such high inductions that the magnetic force $\mathrm{H}$ was a considerable part, numerically, of the induction $\mathrm{H}+4 \pi \mathrm{I}$.

* Partly communicated to the Physikalische Gesellschaft of Berlin on June 28, 1895.

+ Communicated by the Author, in continuation of the paper on "Electromagnetic Stress," Phil. Mag. March 1895.

$\ddagger$ E. T. Jones, Phil. Mag., March 1895; Wied. Ann. liv. p. 641 (1895).

Stefan, Wien. Ber. lxxxi. 2 Abth. p. 89 (1880).

Phil. Mag. S. 5. Vol. 41. No. 250. March 1896. M 


\section{Apparatus.}

These inductions were obtained by means of the Ring Electromagnet designed by Dr. H. du Bois*.

The chief parts of the apparatus are shown in fig. 1 , by a vertical axial section; the left balf is not all shown, but is symmetrical with the right. The pole-pieces were conical, and had a vertical angle of $78^{\circ} 28^{\prime}$, so that the field near the vertex was as nearly uniform as possiblet.

Both pole-pieces were axially perforated, the width of the openings being about 5 millim.

Into one of the pole-pieces fitted a short cylindrical iron bar, $\mathrm{C}_{1}$, provided with a flange, so that when pressed home it just reached to the vertex of the cone. Into the opening in the other pole-piece fitted a longer bar, $\mathrm{C}_{2}$, of the same iron as $\mathrm{C}_{1}$ and of equal diameter ; this bar could be moved to and fro in its socket with very little friction. The two bars thus met in the equatorial plane $\mathrm{EE}^{\prime}$ and formed an "isthmus" between the pole-pieces. Similar bars were also made of steel.

This part of the apparatus was carefully centred, and the inner ends of the bars were turned plane and polished; in this process the pole-pieces themselves served as "guardrings" before they were completely turned down to their conical form. The surfaces were optically tested as in the former experiments (l.c. p. 262).

The bar $\mathrm{C}_{2}$ was connected, by a long brass rod $\mathrm{M}$ and a cord which passed over a pulley, with a scale-pan, so that the tractive force could be directly measured. For measuring the induction and magnetic force in the isthmus the method of Ewing and Low was employed. A small brass bobbin, on which two coils, each of five turns of thin copper wire, were wound, could be placed on the isthmus near the plane of section, so that when the bar $\mathrm{C}_{2}$ was pulled out the bobbin automatically fell out to a distance and was turned so that its plane remained parallel to the field. The diameter of one of the coils was slightly greater than that of the isthmus, that of the other about 2 millim. greater, so that an annular space about 1 millim. wide existed between the coils. Each coil could be connected through a resistance-box with an Ayrton-Mather galvanometer. The movable coil of this instrument was specially weighted to make it suitable for ballistic measurements.

* Du Bois. Wied. Ann. li. p. 537 (1894); see fig. 11 there.

$\dagger$ Ewing, 'Nagnetic Irduction in Iron and other Metals,' $\$ 97$ (18є3). 


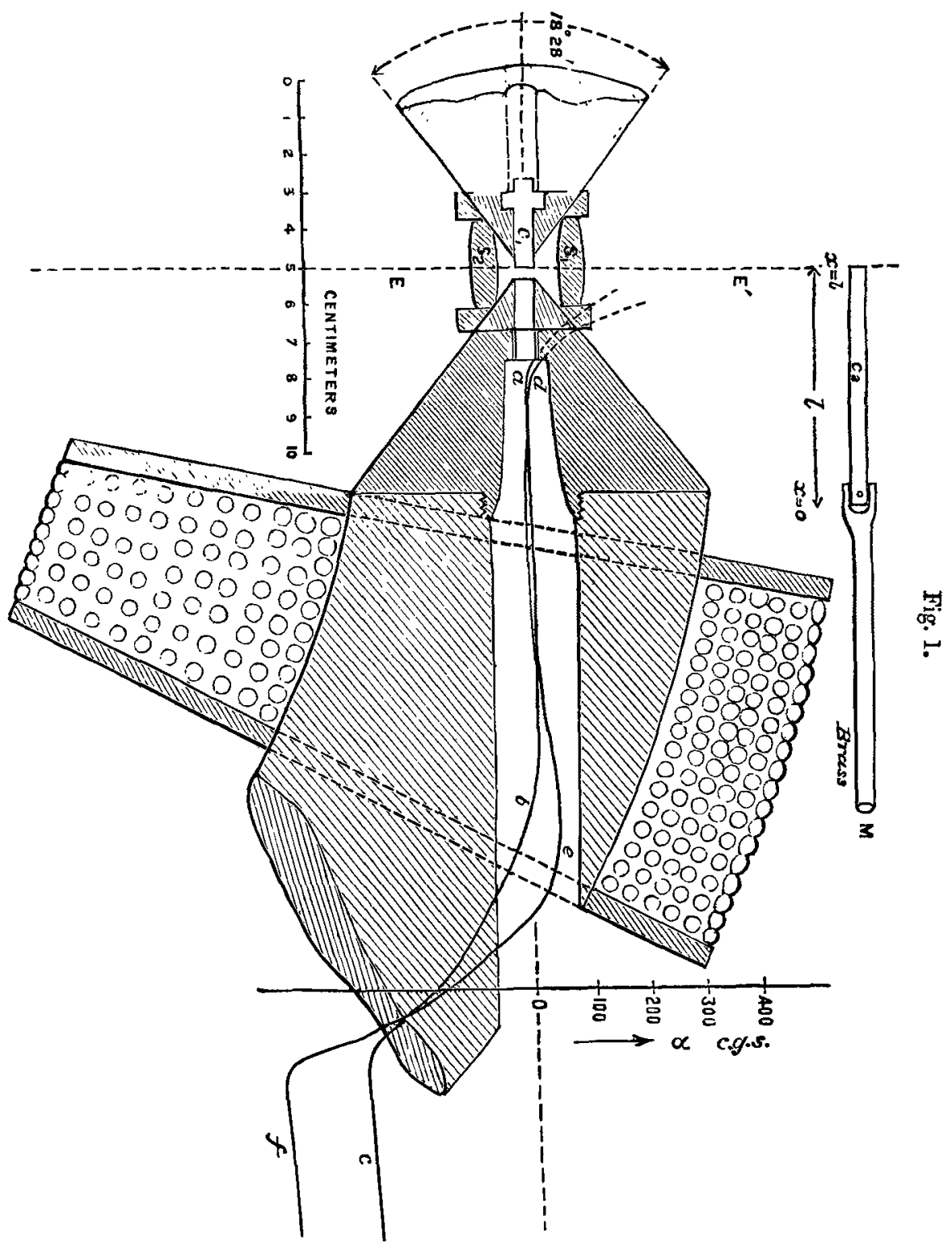


From the induction-throws obtained with the two coils, the mean induction in the isthmus and the field-intensity just outside the isthmus (which by the principle of continuity of tangential magnetic force is equal to the magnetic force just inside the isthmus) could be calculated.

It was assumed that the field in and near the isthmns was so nearly uniform that the induction and magnetic force were constant over the section of the isthmus, and the latter equal to the field in the annular space between the two coils.

\section{Theory.}

The results obtained with this arrangement can be interpreted in the following way according to Maxwell's theory.

The mechanical force $X$ acting in the direction ox on a body magnetized with an intensity whose components are $A, B, C$, and placed in a feeld of magnetic force of components $\alpha, \beta, \gamma$, is *

$$
\mathrm{X}=\mathrm{X}_{1}+\mathrm{X}_{2}+\mathrm{X}_{3}=\iiint\left(\mathrm{A} \frac{d a}{d x}+\mathrm{B} \frac{d \beta}{d x}+\mathrm{C} \frac{d \gamma}{d x}\right) d x d y d z \text {. }
$$

Applying this to the case of the bar $\mathrm{C}_{2}$, taking the origin at the outer end ( $c f$. fig. 1 ) and $o x$ along the axis of the baralso considering for the present only the first term $X_{1}$ of the integral, and assuming that $A$ and $a$ are independent of $y$ and $z$ in each section of the bar-we have after integrating by parts,

$$
\frac{\mathrm{X}_{1}}{\mathrm{~S}}=[\mathrm{A} \alpha]_{0}^{l}-\int_{0}^{l} \alpha \frac{d \mathrm{~A}}{d x} d x,
$$

where $l=$ length, and $S=$ section of the bar.

At the end $(x=l)$ between the pole-pieces we have $\mathrm{A}=\mathrm{I}$, while $\alpha=H+2 \pi \mathrm{I}$, corresponding to the action of the polepieces and of the free end of the bar $\mathrm{C}_{1}$.

The distribution of $\alpha$ along the axis was found by throwing out a small exploring coil from different points on the axis. The results showed that a certain region existed in which $\alpha$ was always very small and nearly constant. The ordinates of the curves $\overline{a b c}$ and $\overline{d e f}$, fig. 1 , represent the values of $a$ at points on the axis, with magnetizing currents of 7 and 25 amp. respectively.

The length of the bar $\mathrm{C}_{2}$ was so chosen that it reached to

* Maxwell, ‘Electricity and Magnetism,' vol. ii. §639. 
this region where the field was practically zero. We have, therefore, at $x=0$, also $\alpha=0$, and the equation becomes

$$
\frac{\mathrm{X}_{1}}{\mathrm{~S}}=\mathrm{I}(\mathrm{H}+2 \pi \mathrm{I})-\int_{0}^{\mathrm{I}} \mathrm{H} d \mathrm{I},
$$

or, remembering the relation $\mathrm{B}=\mathrm{H}+4 \pi \mathrm{I}$,

$$
\frac{\mathrm{X}_{1}}{\mathrm{~S}}=\frac{\mathrm{B}^{2}-\mathrm{H}^{2}}{8 \pi}-\int_{0}^{\mathrm{I}} \mathrm{H} d \mathrm{I} \text {. . . . . }
$$

This part of the integral in (1) depends only on the longitudinal components of the field and magnetization.

It may be shown that the part of $\mathrm{X}$ depending on the transverse components of field and mignetization vanishes if the value of $\alpha$ is constant at the outer end of the bar, i.e. if $\frac{d \alpha}{d x}=0$ at $x=0^{*}$; since this was very nearly the case in the experiments we may neglect these terms.

Equation (2) gives, therefore, the tractive force per unit area ; calling this $\mathrm{P}$ grammes weight per sq. centim., we have

or $†$

$$
\mathrm{P}=\frac{\mathrm{B}^{2}-\mathrm{H}^{2}}{8 \pi g}-\frac{1}{g} \int_{0}^{\mathrm{I}} \mathrm{H} d \mathrm{I} ; . \quad . \quad . \quad .
$$

$$
\frac{\mathrm{B}^{2}}{8 \pi g}=\mathrm{P}+\frac{\mathrm{I}^{2}}{8 \pi g}+\frac{1}{g} \int_{0}^{\mathrm{I}} \mathrm{H} d \mathrm{I} ;
$$

so that the expression

$$
\sqrt{\mathrm{P}+\mathrm{H}^{2} / 8 \pi g+\frac{1}{g} \int_{0}^{\mathrm{I}} \mathrm{H} d \mathrm{I}}, \ldots .
$$

* An approximate calculation based on Laplace's equation in cylindrical coordinates gires

$$
\begin{aligned}
\mathrm{X}_{2}+\mathrm{X}_{3} & =\iiint\left(\mathrm{B} \frac{d \beta}{d \cdot c}+\mathrm{C} \frac{d \gamma}{d v}\right) d x d y d z \\
& =-\frac{1}{16} \pi k r^{4}\left(\frac{d a}{d x}\right)_{x=0}^{2},
\end{aligned}
$$

where $r=$ radins of section of bar, and $k=$ ratio of mean radial magnetization to mean radial " external " magnetizing force.

$t$ In the immediately following section of his treatise $(l . c . \$ 641)$, Maxwell explains these forces by his well-known theory of stresses in a medium, and develops the corresponding stress equations. From these the equation (3) might be more shortly deduced. In somewhat different ways similar expressions have been obtained by du Bois, Wied. $A n n$. xxxv. p. 146 (1888), and by Adler, Wien. Ber. c. 2 Abth. p. 897 (1891). 
in which the first term is generally the greatest, is in the present arrangement, according to Maxwell's theory, proportional to the induction $B$. In the former experiments $B$ was proportional, neglecting small corrections, simply to $\sqrt{ } \overline{\mathrm{P}}$.

The integral $\int_{0}^{\mathrm{I}} \mathrm{H} d \mathrm{I}$ is clearly equal to the area enclosed by the magnetization curve, the axis of $I$, and the line parallel to the $\mathrm{H}$-axis at distance $\mathrm{I}$ from it*. This area is very different in the cases of hard steel and soft iron. For this reason, and in order to make the test as general as possible, two bars of glass-hard steel were also experimented on.

\section{Preliminary Experiments.}

The ballistic galvanometer was standardized in the usual way by means of a long solenoid and a secondary coil.

The core of the solenoid consisted of a glass tube covered with ebonite + ; this was turned accurately cylindrical, and its diameter measured with a Zeiss "thickness measurer," both before and after it was wound with one layer of silkcovered copper wire. From these measurements the field inside the solenoid and the area of the solenoid were calculated in the usual way, The current in the solenoid was measured by a Kelvin " platform "-galvanometer, which was moreover standardized by a copper voltametert.

From the throw of the galvanometer-needle on reversing the primary current, the ballistic sensitiveness of the galvanometer was calculated. This was not constant but varied, firstly somewhat with the time and temperature, secondly with the resistance of the galvanometer circuit. The first changes were observed and corrected for by withdrawing a small coil from a very constant permanent magnet before and after each set of observations.

This was then repeated with various resistances in the galvanometer circuit. At the same time the damping was also observed, $i$. e. the ratio $m$ of two successive swings measured from the zero. The results of these observations are contained in Table 1., in which $R=$ total resistance of galvanometer circuit, $\sigma=$ product of $\mathbf{R}$ into the throw ( $\sigma$ being thus proportional to the ballistic sensitiveness of the galvanometer), and

* Du Bois, Wied. Ann. xxxv. p. 146 (1888); Max Weber, Wied. Ann. liv. p. 35 (1895).

$\dagger$ Ebeling, Reichsanst.-Bericht, Zschr. Instr.-Kunde, xv. p. 331 (1895).

† The instructions given in A. Gray's 'Absolute Mersurements in Electricity and Magnetism,' vol. ii. part ii. p. 421, were observed. 
Magnetic Tractive Force.

$$
\sigma^{\prime}=\sigma\left\{1+0.5(m-1)-0 \cdot 277(m-1)^{2}+0 \cdot 13(m-1)^{3}\right\}^{*} .
$$

$\sigma^{\prime}$ is proportional to the ballistic sensitiveness of the galvanometer corrected for the damping of the oscillations.

TÁble I.-Temp. $21^{\circ} 3$ C.

\begin{tabular}{|c|c|c|c|}
\hline R. & $\sigma$. & $m$. & $\sigma^{\prime}$. \\
\cline { 1 - 2 } $7 \cdot 82$ & 2112 & $1 \cdot 231$ & 2333 \\
$10 \cdot 82$ & 2142 & $1 \cdot 187$ & 2325 \\
$12 \cdot 82$ & 2149 & $1 \cdot 181$ & 2327 \\
1488 & 2164 & $1 \cdot 180$ & 2340 \\
$17 \cdot 82$ & 2165 & $1 \cdot 161$ & 2326 \\
$22 \cdot 82$ & 2191 & $1 \cdot 143$ & 2335 \\
\hline
\end{tabular}

The value of $\sigma^{\prime}$ is therefore within $\frac{1}{2}$ per cent. constant; in other words, the influence of the resistance of the secondary circuit on the ballistic sensitiveness of the galvanometer is completely, though indirectly, explained by its well-known influence on the damping of the oscillations, and can be eliminated, was as done in all the galvanometer observations. Moreover, the damping was too small to have any effect on the proportionality of throw to quantity of electricity flowing through the galvanometer, as I convinced myself by special observations.

The areas of the two isthmus coils were compared electromagnetically in the uniform field between flat pole-pieces with a standard coil made of a single strip of phosphor bronze wound on a circular glass plate which had been carefully turned, ground, and measured. The connecting strips of the standard coil were exactly laid one above the other so as to enclose no area parallel to the plane of the coil.

In using this coil the influence of its resistance on the sensitiveness of the galvanometer was of course, as explained above, taken into account.

The total areas of the two isthmus coils were thus found to be 1.235 and $2.553 \mathrm{sq}$. centim. respectively, that of the standard coil being 1.530 sq. centim. These areas were also calculated from the previously measured diameters of the brass bobbin and of the wire, and the calculated values

* Ayrton, Muther, and Sumpner, Phil. Mag. [5] xxx. p. 69 (1890). 
agreed within $\frac{1}{2}$ and $\frac{1}{3}$ per cent., respectively, with the values obtained electromagnetically.

A series of observations was then made of the tractive force and at the same time of the induction-throws caused by the coils falling from the isthmus, the electromagnet being excited by various currents ranging from 0 to $25 \mathrm{amp}$.

One great difficulty in measuring the tractive force was due to the fact that the iron bar, and, more especially, the steel bar (which in the process of hardening might easily be slightly bent), often got jammed in its socket. If the bar was pulled exactly in the direction of its axis and that of its socket the jamming was avoided, and the friction was very slight. This was determined by removing the other pole-piece and demagnetizing the electromagnet as far as possible in order to remove all magnetic action. By properly guiding the brass rod $M$, the position was then found in which the weight necessary to pull the bar out was a minimum, and this was found to be less than 5 grammes weight, which is negligible in comparison with the tractive forces obtained later.

But if the bar was pulled only slightly to one side, it became jammed in its socket, and about 700 grms. weight more were necessary to pull it out. In all subsequent measurements therefore the position was found, by properly guiding the brass rod, in which the tractive force was a minimum, and this was taken as the magnetic tractive force. The question as to whether the magnetization had any appreciable effect on the friction was tested by pushing the longer bar $\mathrm{C}_{2}$ through both pole-pieces $\left(\mathrm{C}_{1}\right.$ being removed), so that it lay in a symmetrical position of minimum potential energy. No effect on the friction could be detected when the exciting current was made or broken*.

For the graphical evaluation of the integral $\int_{0}^{\mathrm{I}} \mathrm{H} d \mathrm{I}$ it was necessary to have the magnetization-curves for the iron and steel.

The higher values of $\mathrm{H}$ and I were already known from the isthmus experiments. For the determination of the earlier parts of the curves, two bars were used which were cut from the same pieces as the isthmus bars. The curves were then

* This arrangement, in which no gap existed in the isthmus, afforded at the same time a means of testing how far the gap in the usual arrangement caused disturbance by spreading the lines of induction. It was found that in the strong fields here used this was a considerably smaller source of error than might be supposed after certain experiments at less intense fields. 
determined for these by means of a du Bois Magnetic Balance*, which had been tested at the Reichsanstalt. These experiments, as well as all the tractive-force measurements, were made with increasing magnetization $\dagger$. This integral formed only a comparatively small correction, so that it was not necessary to know it very accurately.

\section{Final Experiments.}

From the galvanometer-throws the values of $B$ and $H$ were calculated, and their difference gave, on being divided by $4 \pi$, the magnetization I. The greatest values of I obtained for the soft iron and the hard steel were 1818 C.G.S. and 1556 C.G.S. respectively, and these occurred at a field of about 10,600 C.G.S. At stronger fields I appears to have rather smaller values $\ddagger$; a similar apparent diminution of $I$ was also observed by Ewing $\$$.

It must, however, be remarked that the isthmus method is never very suitable for accurate measurements, and that the arrangement described above is particularly unfavourable to accurate measurements of $I$ from the difference of $B$ and $H$; firstly, because of the disturbing influence of the gap in the isthmus; and, secondly, because the bars are not continuons with the pole-pieces, as in the original arrangement of Ewing and Low.

No valid conclusions can therefore be drawn from these experiments as to the course of the magnetization-curve ; the induction in the isthmus, however, which is the quantity of chief importance in these experiments, was, in consequence of its direct determination, known with sufficient accuracy.

With each value of the current, the measurements were repeated several times. For given values of the galvanometerthrows, the minimum tractive force was very constant, so that even at the highest values it could be determined to within about 30 grammes weight.

The greatest magnetic tractive force measured was 9430 grms. weight, the cross section of the iron bar being $0 \cdot 1896$ sq. centim. This gives a pull of $49 \cdot 73$ kilogs. weight per sq. centim. (707.4 lb. wt. per sq. inch).

* See du Bois, Zeitschr. für Instr.-Kunde, xii. p. 404 (1892).

$\dagger$ 'The curres obtained with the balance will be published in another connexion.

I In later experiments made with a continuous isthmus (see p. 160, footnote) this diminution of I was not observed.

$\S$ Ewing, l.c. $\$ 93$; this was attributed by him to non-uniformity of the field near the isthmus. 
The greatest value of the integral $\frac{1}{g} \int_{0}^{\mathrm{I}} \mathrm{H} d \mathrm{I}$ was in the iron 550 , in the steel 840 grms. weight per sq. centim. This only gives, therefore, a correction of a few per cent. In my former experiments the corresponding correction (there due to the slight non-uniforinity of the field inside the coils) was only about $\frac{1}{2}$ pro mil. (Wied. Ann. l. c. p. 649 , footnote).

TABLE II.-Former results (Phil. Mag. l. c. p. 265).

\begin{tabular}{|c|c|c|c|c|}
\hline $\begin{array}{c}\text { I. } \\
\text { o.G.S. }\end{array}$ & $\begin{array}{c}\text { B. } \\
\text { o.G.s. }\end{array}$ & $\frac{\mathbf{B}}{\sqrt{\sqrt{8 \pi g}}}$. & $\begin{array}{c}\text { G. } \\
\text { Observed. }\end{array}$ & Difference. \\
\hline $\begin{array}{r}493 \\
551 \\
646 \\
853 \\
996 \\
1163 \\
1291 \\
1346 \\
1400 \\
1463 \\
1550 \\
1585\end{array}$ & $\begin{array}{r}6198 \\
6929 \\
8122 \\
10730 \\
12520 \\
14630 \\
16260 \\
16970 \\
17690 \\
18540 \\
19730 \\
20230\end{array}$ & $\begin{array}{r}39 \cdot 2 \\
43 \cdot 9 \\
51 \cdot 6 \\
68 \cdot 1 \\
79 \cdot 4 \\
92 \cdot 9 \\
103 \cdot 3 \\
107 \cdot 7 \\
112 \cdot 3 \\
117 \cdot 7 \\
125 \cdot 3 \\
128 \cdot 4\end{array}$ & $\begin{array}{r}39 \cdot 2 \\
44 \cdot 4 \\
51 \cdot 6 \\
68 \cdot 4 \\
79 \cdot 0 \\
92 \cdot 0 \\
102 \cdot 9 \\
107 \cdot 3 \\
111 \cdot 9 \\
117 \cdot 1 \\
123 \cdot 5 \\
126 \cdot 7\end{array}$ & $\begin{array}{r}0.0 \\
+0.5 \\
0.0 \\
+0.3 \\
-0.4 \\
-0.9 \\
-0.4 \\
-0.4 \\
-0.4 \\
-0.6 \\
-1.8 \\
-1.7\end{array}$ \\
\hline
\end{tabular}

TABLe III.-Annealed Soft Styrian Iron.

\begin{tabular}{|c|c|c|c|c|c|c|}
\hline $\begin{array}{r}\text { Current, } \\
\text { Amperes. }\end{array}$ & $\begin{array}{c}\text { H. } \\
\text { C.G.S. }\end{array}$ & $\begin{array}{c}\text { B. } \\
\text { C.G.S. }\end{array}$ & $\begin{array}{l}\text { I. } \\
\text { c.G.S.S. }\end{array}$ & 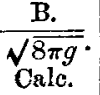 & $\begin{array}{l}\text { G. } \\
\text { Obs. }\end{array}$ & Difference. \\
\hline $\begin{array}{c}0 \\
0 \cdot 13 \\
0 \cdot 37 \\
0 \cdot 93 \\
1 \cdot 33 \\
2 \cdot 6 \\
3 \cdot 8 \\
5 \cdot 6 \\
7 \cdot 9 \\
9 \cdot 8 \\
14 \cdot 9 \\
25 \cdot 0\end{array}$ & $\begin{array}{r}260^{*} \\
613 \\
1440 \\
3470 \\
5070 \\
8560 \\
10520 \\
12720 \\
14230 \\
14850 \\
16030 \\
17690\end{array}$ & $\begin{array}{l}17740 \\
22050 \\
23370 \\
26140 \\
27420 \\
31220 \\
33370 \\
34660 \\
35790 \\
36450 \\
38270 \\
39260\end{array}$ & $\begin{array}{l}1392 \\
1707 \\
1745 \\
1805 \\
1779 \\
1803 \\
1818 \\
1746 \\
1716 \\
1719 \\
1770 \\
1796\end{array}$ & $\begin{array}{l}113 \cdot 0 \\
140 \cdot 5 \\
148 \cdot 9 \\
166 \cdot 5 \\
174 \cdot 7 \\
198 \cdot 9 \\
21 \cdot 2 \cdot 5 \\
220 \cdot 8 \\
227 \cdot 9 \\
232 \cdot 1 \\
243 \cdot 8 \\
250 \cdot 1\end{array}$ & $\begin{array}{l}109 \cdot 5 \\
138 \cdot 0 \\
147 \cdot 0 \\
162 \cdot 0 \\
172 \cdot 0 \\
195 \cdot 0 \\
207 \cdot 5 \\
219 \cdot 5 \\
228 \cdot 3 \\
232 \cdot 8 \\
239 \cdot 8 \\
250 \cdot 9\end{array}$ & $\begin{array}{l}-3.5 \\
-2.5 \\
-1.9 \\
-4.5 \\
-2.7 \\
-39 \\
-5.0 \\
-1.3 \\
+0.4 \\
+0.7 \\
-4.0 \\
+0.8\end{array}$ \\
\hline
\end{tabular}

* Due to residual magnetisia in the pole-pieces. 
TABLE IV.-Glass-hard Wolfram Steel.

\begin{tabular}{|c|c|c|c|c|c|c|}
\hline $\begin{array}{c}\text { Current, } \\
\text { Amperes. }\end{array}$ & $\begin{array}{c}\text { H. } \\
\text { o.G.S. }\end{array}$ & $\begin{array}{c}\text { B. } \\
\text { C.G.S. }\end{array}$ & $\begin{array}{l}\text { I. } \\
\text { o.G.S. }\end{array}$ & 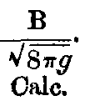 & $\begin{array}{l}\text { G. } \\
\text { Obs. }\end{array}$ & Difference. \\
\hline $\begin{array}{l}0 \\
v \cdot 13 \\
0 \cdot 37 \\
0 \cdot 91 \\
1 \cdot 31 \\
26 \\
3 \cdot 8 \\
5 \cdot 7 \\
8 \cdot 0 \\
9 \cdot 9 \\
14 \cdot 9 \\
25 \cdot 0\end{array}$ & $\begin{array}{r}181^{*} \\
558 \\
1615 \\
3470 \\
5050 \\
8670 \\
10750 \\
12830 \\
14220 \\
14860 \\
15970 \\
17830\end{array}$ & $\begin{array}{l}11390 \\
17550 \\
19750 \\
22510 \\
24000 \\
27950 \\
30290 \\
31950 \\
32860 \\
33470 \\
35380 \\
36110\end{array}$ & $\begin{array}{r}892 \\
1353 \\
1444 \\
1516 \\
1508 \\
1535 \\
1556 \\
1522 \\
1484 \\
1481 \\
1545 \\
1456\end{array}$ & $\begin{array}{r}72.5 \\
111 \cdot 8 \\
125.8 \\
143.4 \\
1529 \\
178.0 \\
193.0 \\
203.5 \\
2093 \\
213 \cdot 1 \\
225.4 \\
230.0\end{array}$ & $\begin{array}{r}71 \cdot 8 \\
107 \cdot 3 \\
121 \cdot 3 \\
139 \cdot 0 \\
148 \cdot 7 \\
174 \cdot 6 \\
187 \cdot 6 \\
201 \cdot 1 \\
207 \cdot 3 \\
211 \cdot 3 \\
221 \cdot 9 \\
230 \cdot 2\end{array}$ & $\begin{array}{l}-0.7 \\
-4.5 \\
-4.5 \\
-4.4 \\
-4.2 \\
-3.4 \\
-5.4 \\
-2.4 \\
-2.0 \\
-1.8 \\
-3.5 \\
+0.2\end{array}$ \\
\hline
\end{tabular}

* Due to residual magnetism in the pole-pieces.

Tables III. and IV. contain the values of the exciting current, $\mathrm{H}, \mathrm{B}, \mathrm{I}, \mathrm{B} / \sqrt{8 \pi g}$, of the quantity

$$
\mathrm{G}=\sqrt{\mathrm{P}+\frac{\mathrm{H}^{2}}{8 \pi g}+\frac{1}{g} \int_{0}^{\mathrm{I}} \mathrm{H} d \mathrm{I}}
$$

and, lastly, of the difference

$$
\mathrm{G}-\frac{\mathrm{B}}{\sqrt{8 \pi g}}
$$

in iron and steel.

Table II. contains the results of my former experiments (l.c. p. 265), which are here reproduced in order to show the complete range experimented over.

The results are also exhibited graphically in fig. 2 , in which the points,$+ \odot$, show the values of $G$ as a function of $\mathrm{B}$ in iron and steel respectively, while the straight line represents the function $\mathrm{B} / \sqrt{8 \pi g}$.

The points * are taken from the former experiments, and represent the square root of the tractive force per sq. centim., which in that case was theoretically equal to $\frac{\mathrm{B}}{\sqrt{8 \pi g}}$.

All the observed points lie near the straight line; the greatest difference is about 3 per cent. Most of the points lie under the line; this is probably due to the spreading action of the gap in the isthmus, which diminishes the tractive 


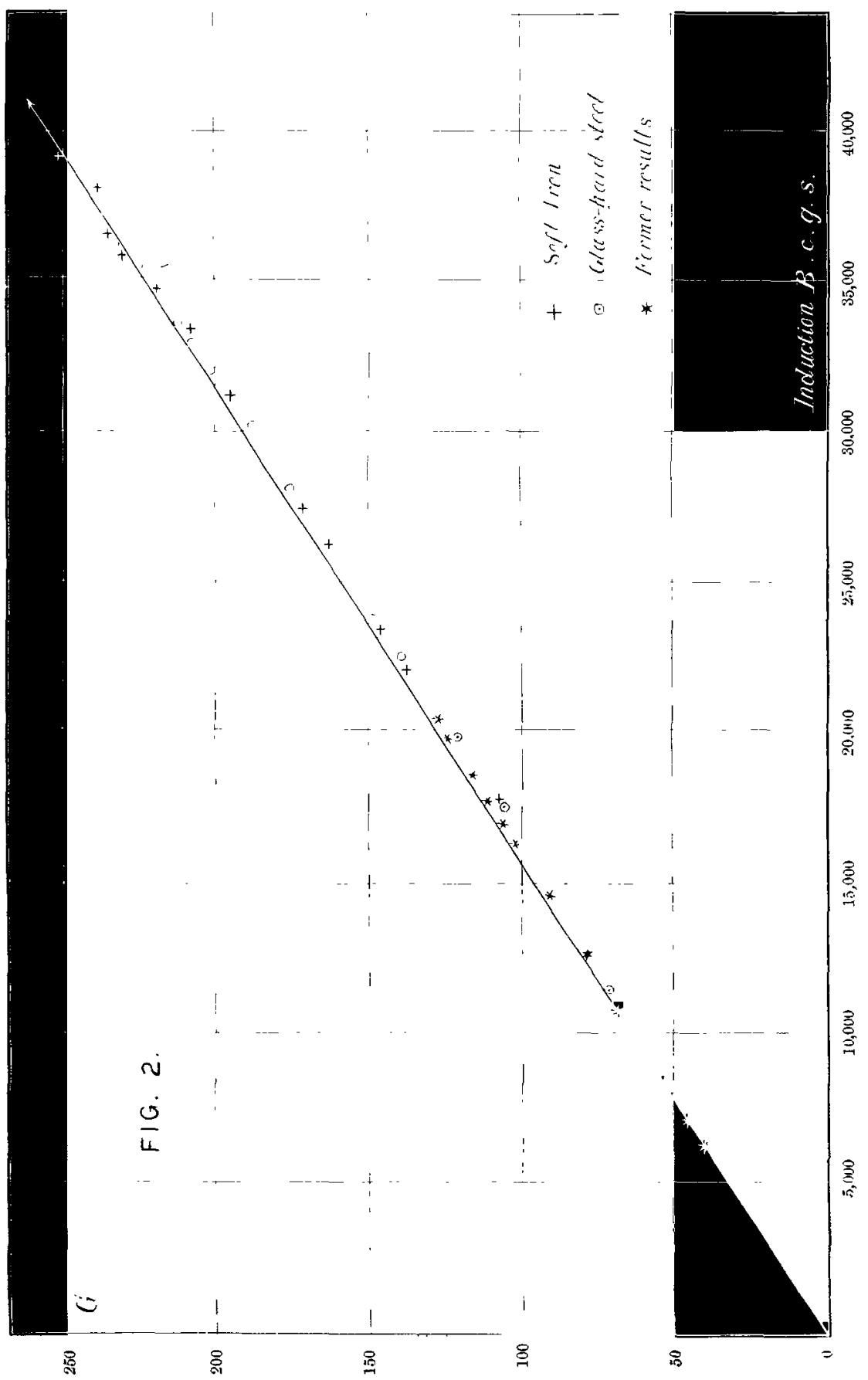


force. The agreement is, however, on the whole such that the equation (3)

$$
\mathrm{P}=\frac{\mathrm{B}^{2}-\mathrm{H}^{2}}{8 \pi g}-\frac{1}{g} \int_{0}^{\mathrm{I}} \mathrm{H} d \mathrm{I}
$$

can be regarded as verified.

According to Maxwell's theory (l. c. $\S 643$ ) the first term $\frac{\mathrm{B}^{2}}{8 \pi y}$

air-gap between the ends of the two bars ; similarly, $\mathrm{H}^{2} / 8 \pi g$ is the tension in the gap, depending only on the "external" field $H$. The correctness of this interpretation of the term $\mathrm{H}^{2} / 8 \pi g$ follows from the well-known experiments of Quincke and others.

This latter part of the stress is not included in the tractive force in the present arrangement : it merely serves to compress the brass pillars $S_{1}, S_{2}, S_{3}$.

If the bar $\mathrm{C}_{2}$ were firmly fixed in its pole-piece (instead of sliding in it), and if the two halves of the electromagnet were pulled from each other, the pull in grammes weight in this case, corrected for the tension due to all those tubes of induction which do not pass along the isthmus, would be equal to

$$
\frac{\mathrm{B}^{2}}{8 \pi g} \times \text { area of contact. }
$$

This case corresponds theoretically to the arrangement of my former experiments, but cannot of course be practically carried out.

\section{Measurement of High Inductions.}

After Maxwell's law of tractive force, or electromagnetic stress, had been verified as explained above for inductions up to 40,000 C.G.S., its general truth could be assumed. And just as various physicists have conversely used the tractive force for the measurement of lower inductions, it now seemed feasible to apply a similar process to the measurement of the highest attainable inductions, all other known methods failing in this case.

I therefore arranged a fow more experiments with this object. Two pole-pieces of $120^{\circ}$ vertical angle were made of the very best annealed Swedish iron. The point of one was slightly flattened, ground plane, and polished, so that it presented a small circular pole-face whose diameter was only a fraction of a millimetre. Through the opposite pole-piece a slightly conical hole was bored, through which a long wire of 
annealed soft iron (of diameter 0.586 millim.) could be drawn, which fitted accurately in front and more loosely behind. The friction was thus only a fraction of 1 gramme weight.

The end of the wire was also carefully polished and, as well as the opposite small pole-face, examined and measured with a Zeiss microscope.

With a magnetizing current of 25 amperes, the weight supported in this case was 249 grms. weight ; this corresponds to a pull of 92.39 kilogs. weight per sq. centim. (1314 lb. wt. per sq. inch).

The maximum value of the magnetization was, moreover, determined by means of an isthmus consisting of a bundle of 50 pieces of the same wire pushed through the former polepieces of $78^{\circ} 28^{\prime}$ vertical angle. This value was found to be about 1800 C.G.S.

Taking also 500 grms. weight as the approximate value of the integral $\frac{1}{g} \int_{0}^{I} \mathrm{H} d \mathrm{I}$, we have from these data the values of $\mathrm{B}^{2}-\mathrm{H}^{2}$, and of $\mathrm{B}-\mathrm{H}=4 \pi \mathrm{I}$; from these were deduced the values

$$
\begin{aligned}
& B=61,900 \text { C.G.S. } \\
& H=39,300 \quad "
\end{aligned}
$$

These experiments were extended still further by drawing out the wire to a thickness of 0.2412 millim., and narrowing down the hole in the pole-piece correspondingly.

After the wire had been once more annealed in a spirit-flame and its end ground plane, the weight supported with a current of 40 amperes was 52.5 grms. weight, corresponding to a pull of $114 \cdot 9$ kilogs. weight per sq. centim. (1634 lb. wt. per sq. inch).

Hence follow, as above, the values

$$
\begin{aligned}
& B=74,200 \text { C.G.S. } \\
& H=51,600 \quad,
\end{aligned}
$$

and the permeability is only

$$
\mu=\mathrm{B} / \mathrm{H}=1 \cdot 44 \text {. }
$$

The calculated value of $\mathrm{H}$ from the Stefan-Ewing logarithmic formula is 50,450 C.G.S., assuming that the conical pole-pieces are uniformly magnetized with a maximum intensity of 1800 C.G.S. To this must be added about 750 C.G.S. due to the direct action of the coils of the electromagnet with 
a current of 40 amperes. The total calculated field is thus 51,200 C.G.S.; which agrees well with the value found above.

In this experiment the area of the isthmus was about $\frac{1}{200.000}$ of the area of the base of the conical pole-piece.

This induction $(B=74,200)$ exists also by continuity in the narrow air-gap at the contact, and here it is to be regarded as "external" field. This will not be much altered at the moment of separation as long as the gap is narrow in comparison with its transverse dimension. It was then observed with a magnifying glass that, unless the apparatus was very carefully cleaned, small microscopical iron filings flew into the gap when separation took place and formed new "isthmuses" arross it, whose thickness was very small in comparison with that of the $\frac{1}{4}$ millim. iron wire, so that their self-demagnetizing effect could be neglected. The induction $B^{\prime}$ in these is thus

$$
\mathrm{B}^{\prime}=74200+4 \pi .1800=96,800 \text { C.G.S. }
$$

We may therefore conclude that inductions of nearly 100,000 C.G.S. can exist in iron without any special occurrence.

If the wire is pulled back so that its end is in the plane of the edge of the opening, the field between the pole-faces is then about 60,000 C.G.S.; it only extends, however, over a few tenths of a millimetre*.

At the instant of separation a tension of $(74200)^{2} / 8 \pi g=224$ kilogs. weight per square centim. (3185 lb. wt. per sq. inch) is transmitted across the air-gap; this is about the limit of elasticity of lead. In this connexion it is interesting to remember that the tension between the plates of an aircondenser at atmospheric pressure cannot far exceed 2 grms. weight per square centim. without a spark appearing. An absolute vacuum, however, or a body of high specific inductive capacity can transmit much greater tensions.

My best thanks are due to Dr. H. du Bois, in whose laboratory the above experiments were carried out, for his help and advice.

Berlin, Christmas, 1895.

* If the field extends over several millimetres an intensity of over 40,000 C.G.S. can scarcely be reached. See du Bois, Wied. Ann. 1. p. 547 (1894) ; J. B. Henderson, Phil. Mag. Nov, 1894. 